\title{
Polyethylene-layered silicate nanocomposites prepared by the polymerization-filling technique: synthesis and mechanical properties
}

\author{
Michael Alexandre ${ }^{\mathrm{a}}$, Philippe Dubois ${ }^{\mathrm{a}}$, Tao Sun ${ }^{\mathrm{b}}$, Juan M. Garces ${ }^{\mathrm{b}}$, Robert Jerôme ${ }^{\mathrm{a}, *}$ \\ ${ }^{a}$ Center for Education and Research on Macromolecules (CERM), University of Liège, Sart-Tilman, B6, B-4000 \\ Liège, Belgium ${ }^{\mathrm{b}}$ The Dow Chemical Company, Corporate R and D, 1776 Building, Midland, Ml 48674, USA
}

\begin{abstract}
Polyethylene-layered silicate nanocomposites were prepared by the in situ intercalative polymerization of ethylene by the so-called polymerization-filling technique and analyzed by transmission electron microscopy (TEM), X-ray diffraction analysis (XRD), differential scanning calorimetry, dynamic mechanical analysis and tensile testing. Non-modified montmorillonite and hectorite were first treated by trimethylaluminum-depleted methylaluminoxane before being contacted by a Ti-based constrained geometry catalyst. The nanocomposite was formed by addition and polymerization of ethylene. In the absence of a chain transfer agent, ultra high molecular weight polyethylene was produced. The tensile properties of these nanocomposites were poor and essentially independent of the nature and content of the silicate. Upon hydrogen addition, the molecular weight of the polyethylene was decreased with parallel improvement of the tensile and shear moduli, in relation to the filler content. The exfoliation of the layered silicates was confirmed by XRD analysis and TEM observation. The mechanical kneading of the molten nanocomposites resulted in the partial collapse of the exfoliated structure driven by the thermodynamic stability of the layered filler.
\end{abstract}

Keywords: Polymerization-filling technique; Nanocomposite; Metallocene

\section{Introduction}

Polymer-layered silicate nanocomposites are a new class of organic polymer matrices modified by $1 \mathrm{~nm}$ thick alumi-nosilicate platelets with other dimensions in the 100-1000 nm range. These particles, with a very high aspect ratio, strongly modify the macroscopic properties of the polymer even though a tiny amount of filler is used. A broad range of properties are indeed improved, such as Young's modulus, barrier properties, thermal stability together with flame resistance and heat distortion temperature [1-4].

Basically, nanocomposites can exhibit two extreme morphologies. In an intercalated structure, the polymer is sandwiched in between the silicate layers, so forming a highly ordered arrangement of alternating inorganic and organic layers. In the opposite, the exfoliated (delaminated) structure shows the constitutive silicate layers completely dispersed within the polymer matrix. In order to favor these morphologies, long chain alkylammonium cations are exchanged for the constitutive cations $\left(\mathrm{Na}^{+}, \mathrm{Li}^{+}, \ldots\right)$ of the layered silicates, making the silicate surface more lipophilic and prone to interact with the organic polymer. Three distinct strategies can be used to prepare nanocomposites. The first one consists in dispersing the layered silicate within a solution of the polymer in an organic solvent followed by either the solvent evaporation or the polymer precipitation [5-7]. The main limitations of this technique are the need for large amounts of the organic solvent to insure good clay dispersion together with the use of polymers soluble in conventional solvents. In addition, this method often leads to poor filler dispersion. The second strategy is the melt intercalation of the polymer into previously organo-modified silicates. This method has proved efficiency in the case of polymers, such as nylon-6, polysiloxane and even polystyrene. When the formation of poly-olefin-based nanocomposites is concerned [8-11] a third component has to be added, such as maleic anhydride grafted polypropylene (PP), which improves the polyole-fin-filler interactions $[12,13]$. The third strategy is based on the intercalative polymerization of the monomer. In this technique, the monomer [14-16], together with the polymerization initiator or catalyst [17-19], is intercalated within the silicate layers and the polymerization is initiated either thermally or chemically. This method allows the formation of nanocomposites-based on quite apolar polymers such as polyolefins. The lesspolar monomers which undergo a smaller entropic loss while diffusing in the interlayer spacing can intercalate more easily than their respective polymers. Once there, they can be polymerized to create polymer chains within the interlayers. This intercalation technique was first used by Tudor et al. who intercalated a cationic zirconocene catalyst [17] into a synthetic layered silicate. After addition of methylaluminoxane (MAO), propylene was oligomerized. No structural characterization of the filled PP was, however, reported. Recently, Heinemann et al. [20] prepared nanocomposites of high density polyethylene (HDPE) and linear low density polyethylene (LLDPE) as a result of the polymerization of ethylene and long chain $\alpha$-olefins by various catalytic systems in the presence of dispersed organo-modified silicates. Intercalation and exfoliation were assessed by X-ray diffraction analysis (XRD) and transmission electron microscopy (TEM). Finally, Bergman et al. [19] reported on the in situ intercalative polymerization of ethylene and propylene promoted by a Brookhart-type catalyst 
previously intercalated in an organo-modified fluoro-hectorite. Although the catalytic activity was quite low, exfoliated nanocomposites were prepared.

This paper reports on the in situ intercalative polymerization of ethylene in non-modified layered silicates (synthetic hectorite and natural montmorillonite) by the polymerization-filling technique (PFT). This technique consists in attaching the polymerization catalyst to the surface and into the interlayers of the silicate and polymerizing ethylene in situ. MAO/metallocene complex will be used in this study, the MAO constituent being previously reacted with the non-modified layered silicate.

\section{Experimental}

\subsection{Materials}

The (ferf-butylamido) dimethyl (tetramethyl- $\eta^{5}$-cyclopen-tadienyl) silane titanium dimethyl (CGC) catalyst was a gift from the Dow Chemical Company. It was used as an heptane solution, whose Ti concentration was measured by colori-metric titration $\left(5.21 \times 10^{-3}\right.$ and $5.06 \times 10^{-3} \mathrm{~mol} / 1$ depending on the experiments). MAO was purchased from Witco as a $10 \mathrm{wt} \%$ solution in toluene $(1.65 \mathrm{M}$ in $\mathrm{Al}$ as given by Witco). Ethylene (99.95\%) and hydrogen (99.999\%) were purchased from Air Liquid. Ethylene was dried over molecular sieves and hydrogen was used as received. Heptane and xylene were distilled over $\mathrm{Na}$ just prior to use, and toluene was used freshly distilled over $\mathrm{Na}$ /benzophenone complex. Two layered silicates were studied in this work: natural montmorillonite (Swy-1 from the University of Missouri, Crook County, WY, USA) and synthetic hectorite (Laponite RD from Southern Clay Products, USA). The two clays were prepared as follows, prior to MAO treatment: dispersion in water, elimination of non-swollen particles by decantation and isolation of the purified layered silicate by freeze-drying. Kaolin (Satintone W/Whitex, mean size: $1.4 \mu \mathrm{m}$, Engelhardt) was used as received.

\subsection{Filler treatment}

The filler (dried under reduced pressure $\left(10 \mathrm{~mm} \mathrm{Hg}\right.$ ) at $105^{\circ} \mathrm{C}$ for $16 \mathrm{~h}$ ) was suspended in $100 \mathrm{ml}$ of dried $n$ heptane or more, depending on the type of suspension and the amount of filler (from 2.45 to $3.06 \mathrm{~g}$ )in order to reach ca. 2.5\% dispersion (mass/vol.). The trimethylaluminum (TMA) content of MAO was depleted by distillation. The obtained solid MAO was then dissolved in a given volume of dried toluene. This pretreatment proved to favor the MAO fixation onto the filler particles [21]. The MAO solution was then added with the filler suspension and allowed to react for $1 \mathrm{~h}$ at room temperature. In order to improve the MAO fixation, the solvent was then evaporated and the filler particles were heated under reduced pressure at $150{ }^{\circ} \mathrm{C}$ for $2 \mathrm{~h}$. They were then washed twice with dried toluene $(2 \mathrm{X} 100 \mathrm{ml})$ at $80{ }^{\circ} \mathrm{C}$ in order to eliminate the excess of unbound MAO. Finally, they were suspended in at least $100 \mathrm{ml}$ of dried n-heptane.

\subsection{Ethylene polymerization}

The ethylene polymerization was conducted in a $2 \mathrm{~L}$ stainless steel reactor (Zipperclave ${ }^{\mathrm{TM}}$, Autoclave Engineers Europe). The temperature was regulated by a heating mantle and an internal cold water circuit. A Dispersimax ${ }^{\circledR}$ turbine was used to disperse efficiently the gaseous monomer within the solvent. The polymerization reactor was first dried by heating up to $105^{\circ} \mathrm{C}$ under vacuum for $2 \mathrm{~h}$, and then cooled down to $70{ }^{\circ} \mathrm{C}$ under ethylene flow. $1,250 \mathrm{ml}$ of dry $n$-heptane was added via a Teflon capillary under a nitrogen overpressure. The MAO pretreated filler previously aged for $1 \mathrm{~h}$ at $70{ }^{\circ} \mathrm{C}$ with a given amount of CGC, was added into the reactor at $70{ }^{\circ} \mathrm{C}$ through the teflon capillary. If needed, hydrogen was added by using an addition bomb ( $160 \mathrm{ml}, 0.3 \mathrm{bar})$. Polymerization started upon admission of ethylene (10 bar), whose consumption was followed by a mass flowmeter. Polymerization was stopped by releasing the pressure and cooling down the reactor vat simultaneously. The filled polyethylene was precipitated in acetone with a few drops of aqueous $\mathrm{HCl}$ added, filtered off and dried under reduced pressure at $70^{\circ} \mathrm{C}$ for one night.

\subsection{Characterization}

Thermogravimetric analysis (TGA) was carried out under dry air with a TA 951 thermogravimetric analyser with a heating rate of $10^{\circ} \mathrm{C} / \mathrm{min}$ from room temperature up to $700{ }^{\circ} \mathrm{C}$. The percentage of residual ashes (filler) was taken as the value reported at $600{ }^{\circ} \mathrm{C}$. Differential scanning calorimetry (DSC) was carried out under nitrogen with a TA $910 \mathrm{DSC}$, the data being reported for the second heating run from -150 to $220{ }^{\circ} \mathrm{C}$ at $20{ }^{\circ} \mathrm{C} / \mathrm{min}$. DSC temperature calibration was carried out with indium. SEC measurements were carried out in 1,2,5trichlorobenzene at $135^{\circ} \mathrm{C}$. Melt flow index was measured with a CEAST $6542 / 000$ melt flow indexer according 
to the ASTM D1238 norm. Samples of composites were molded at $200{ }^{\circ} \mathrm{C}$ under 15 tons for 7 min (sample codes: LD 1, 3 and 4) or for 14 min (LD 2, 5-13). The molded plates were cooled down under the same pressure at the temperature of tap water. Dumbbell shaped testing samples were cut from the molded plates and used for tensile testing at least $24 \mathrm{~h}$ after molding. Tensile testing was repeated for at least four samples at an extension speed of $20 \mathrm{~mm} / \mathrm{min}$ with an initial distance between grips of $30 \mathrm{~mm}$ (Dumbbell dimensions: overall length $=69$ $\mathrm{mm}$, length of the flat section $=16 \mathrm{~mm}$, length of the ductile section $=19.2 \mathrm{~mm}$, width of the flat section $=5 \mathrm{~mm}$, thickness $=2 \mathrm{~mm})$. Dynamic mechanical analysis (DMA) was carried out with a TA 983 equipment at fixed frequency $(1 \mathrm{~Hz})$ and deformation amplitude $(0.30 \mathrm{~mm})$ with a heating rate of $2{ }^{\circ} \mathrm{C} / \mathrm{min}$ between -120 and 150 ${ }^{\circ} \mathrm{C}$, the sample dimensions between the clamps being 10 X 10 X $2 \mathrm{~mm}$. XRD was measured using a Siemens D5000 diffractometer with the $\mathrm{Cu} K \alpha$ radiation $(\lambda=0.15406 \mathrm{~nm})$ from 1.5 to $30^{\circ}$ by step of $0.04^{\circ}$. Transmission electron micrographs were obtained with a Philips CM100 apparatus using an acceleration voltage of $100 \mathrm{kV}$. The samples were $80 \mathrm{~nm}$-thick and prepared with a Reichert-Jung Ultracut3 E, FC4E ultra cryo-microtome cutting at $-130^{\circ} \mathrm{C}$.

Table 1

Ethylene polymerization at high pressure $(\mathrm{k}=$ kaolin, $\mathrm{h}=$ hectorite, $\mathrm{mo}=$ montmorillonite, polymerization conditions: $3 \mathrm{~g}$ of filler in $1200 \mathrm{ml}$ $n$-heptane under 10 bar ethylene at $70{ }^{\circ} \mathrm{C}$ )

\begin{tabular}{|c|c|c|c|c|c|c|c|}
\hline Sample & Filler & MAO X $10^{-3}$ mole & $\mathrm{CGClX10^{-6 } \text { mole }}$ & $\mathrm{Al} / \mathrm{Ti}$ initial ratio & Filler loading $(\mathrm{wt} \%)$ & PE yield $(\mathrm{g})$ & Activity (kg PE/g Ti/h) \\
\hline$\overline{\mathrm{LD} 1}$ & None & 24.75 & 15.63 & 1580 & 0.0 & ca. 70 & ca. 50 \\
\hline LD2 & $\mathrm{k}$ & 23.76 & 16.19 & 1470 & 2.3 & 81.3 & 89.0 \\
\hline LD4 & mo & 27.22 & 12.50 & 2180 & 3.3 & 71.7 & 164.7 \\
\hline LD5 & $\mathrm{h}$ & 19.80 & 13.66 & 1450 & 3.8 & 71.6 & 129.5 \\
\hline LD6 & $\mathrm{h}$ & 19.80 & 13.66 & 1450 & 4.0 & 70.1 & 108.0 \\
\hline LD8 & mo & 19.80 & 13.66 & 1450 & 4.1 & 66.7 & 102.4 \\
\hline LD9 $^{\text {a }}$ & $\mathrm{h}$ & 23.76 & 16.19 & 1470 & 3.4 & 83.9 & 49.4 \\
\hline $\mathrm{LD} 10^{\mathrm{a}}$ & $\mathrm{h}$ & 23.76 & 30.75 & 770 & 4.5 & 88.2 & 40.0 \\
\hline $\mathrm{LDll}^{\mathrm{a}, \mathrm{b}}$ & $\mathrm{h}$ & 23.76 & 16.19 & 1470 & n.d. & n.d. & ca. 0 \\
\hline $\operatorname{LD} 12^{\mathrm{a}, \mathrm{c}}$ & $\mathrm{h}$ & 23.76 & 30.75 & 770 & 13.0 & 21.1 & 21.6 \\
\hline $\operatorname{LD} 13^{\mathrm{a}, \mathrm{d}}$ & $\mathrm{h}$ & 33.00 & 30.75 & 1075 & 11.4 & 31.5 & $<7.4$ \\
\hline
\end{tabular}

0.3 bar $\mathrm{H}_{2}$.

${ }^{b}$ High temperature treatment in xylene at $120^{\circ} \mathrm{C}$.

c MAO addition in toluene instead of heptane.

d Non-dried filler, without any treatment at high temperature.

\section{Results and discussion}

\subsection{Composite preparation}

A series of composites have been synthesized in a stain-

less steel reactor by the PFT catalyzed by a complex of Ti-based constrained geometry catalyst and MAO (see Section 2). The experimental conditions are listed in Table 1.

\subsubsection{Effect of the filler nature}

First of all, polyethylene has been synthesized in the absence of filler in order to check the suitability of the experimental conditions for the synthesis of ca. $70 \mathrm{~g}$ of HDPE (LD 1). For comparison, a kaolin-based composite LD 2 ('microcomposite') has been prepared. A filler content as low as $2.3 \mathrm{wt} \%$ was obtained, which is a typical value for the low-filled composites considered in this study. Hectorite, a typical clay used to produce nanocomposites has been used with success, leading to a composite of low filler content (LD 3, 4.2 wt \% filler). LD 4 is a composite containing $3.3 \mathrm{wt} \%$ montmorillonite, another clay usually studied for nanocomposite preparation.

In order to check the reproducibility of these clay-based syntheses, the same experiment was twice repeated, i.e. LD 5 (3.8 wt $\%$ filler) and LD 6 (4.0 wt \% filler) in the case of hectorite and LD 7 (3.9 wt $\%$ filler) and LD 8 (4.1 $\mathrm{wt} \%$ filler) with montmorillonite. No significant change in the composition was observed which is indicative of good reproducibility.

\subsubsection{Effect of a chain tranfer agent}

The molecular characteristics of polyethylene were also tuned by addition of a controlled amount of hydrogen to 
the polymerization medium. The composite LD 9 ( $3.4 \mathrm{wt} \%$ hectorite) was accordingly prepared.

\subsubsection{Effect of the filler treatment}

The experimental conditions for the filler treatment have also been changed in order to check how far the properties of the final nanocomposites can be modified. The effect of

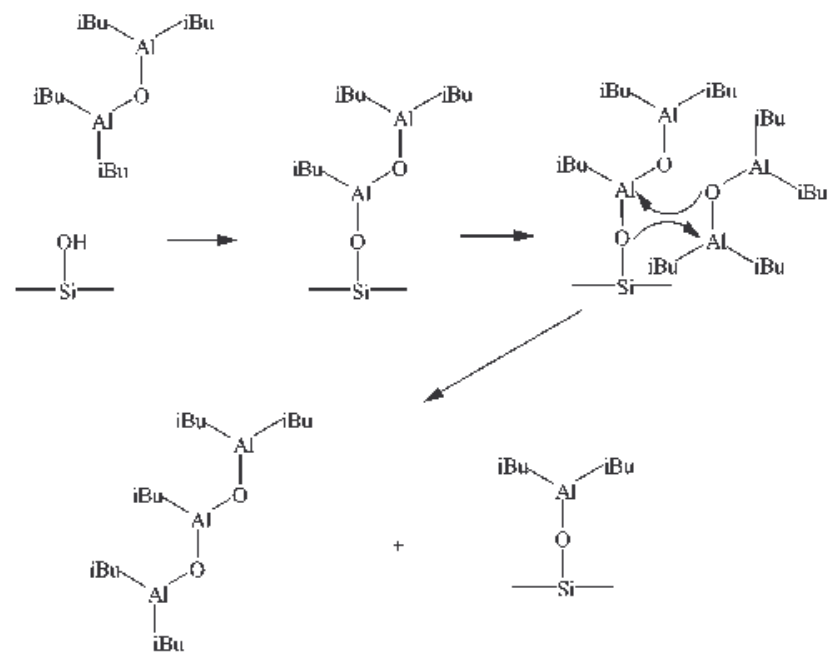

Fig. 1. Sketch for deactivation of the aluminoxane modified surface of silicate.

the Al/Ti molar ratio has been investigated (LD 9 and 10). The high temperature treatment $\left(120{ }^{\circ} \mathrm{C}\right)$ of the activated hectorite has been conducted in a wet environment (xylene) rather than in the dry state, followed by filtration and repeated washings with toluene in the case of LD 11. LD 12 sample has been produced under the same conditions as LD 9 and 10 except for the initial addition of MAO that was carried out in a toluene suspension of hectorite rather than in heptane. Finally, LD 13 sample has been prepared using less drastic conditions. Indeed, in this case, the filler was not previously dried, but a large amount of MAO was added, the excess of which was being used as a scavenger of proto-nic compounds. In this last experiment, the filler treatment was also carried out at $80^{\circ} \mathrm{C}$ for $2 \mathrm{~h}$, directly followed by repeated washing with toluene, therefore skipping the high temperature treatment.

\subsection{Catalytic activity}

When examining the synthesis results, it is first worth noting that the measured catalytic activity is higher when the catalytic complex is attached to the filler rather than dispersed in the solvent, all the other conditions being the same (comparison of LD 1 with LD 2-8). The less important fouling of the reactor could explain this observation. The best catalytic activities are reported for the LD 4, 5 and 7 experiments. Polymerization from montmorillonite seems

to enhance the activity compared to hectorite. The lower activity measured when kaolin is the filler (LD 2) can be explained by the lower amount of MAO that can be attached to this type of filler (see later). The loss in activity when hydrogen is used to regulate the polymerization (LD 9) is in contrast to usually observed improvement obtained with more common fillers (kaolin, magnesium hydroxide, etc.) [22]. Smaller MAO/CGC molar ratio (LD 10 compared to LD 9) has no favorable effect on the polymerization activity, indicating that lower amounts of MAO are sufficient to promote the formation of effective catalytic centers.

No polymerization is observed in the LD 11 experiment, more likely because a large amount of Al species is eliminated during the filtration, so resulting in a too low amount of MAO fixed onto the filler (see later). The same kind of observation was reported by Letourneur when silica surface was treated with isobutylaluminoxane, a well defined analog of MAO. This low amount of fixed Al was explained by the reorganization of the aluminoxane structure according to Fig. 1 [23]. This rearrangement is more favorable at high temperature in a good solvent for the aluminoxane derivatives. The 'Al-O-Si' species ultimately attached to the filler are unable to form catalytically active species when reacted with CGC. Furthermore, active MAO moieties are driven in solution and thus eliminated by the subsequent washings with toluene.

LD 12 shows a limited activity, which is apparently related to the addition of the TMA-depleted MAO onto the filler suspension in toluene rather than in heptane.

LD 13, prepared under milder conditions does not show high polymerization activity indicating that the high temperature treatment of the filler is a prerequisite for the production of low-filled composites.

The quantity of MAO fixed onto the nanofiller has been determined for the LD 5 (hectorite) and LD 7 
(montmoril-lonite) experiments. It has been calculated by subtracting from the initial amount of MAO introduced, both the quantity of TMA distilled off during solvent evaporation (and high temperature treatment) and the amount of MAO washed out with hot toluene after the high temperature treatment. TMA and MAO were quantitatively analyzed by complexometric back-titration of a known excess of EDTA by $\mathrm{Zn}^{2+}$ in the presence of xylenol orange at $\mathrm{pH}=4.8$. Results are shown in Table 2. It appears that, in both cases, MAO is almost quantitatively attached to the filler. This is in clear contrast to what happened in case of kaolin for example [21]. Under similar filler treatment conditions, $15 \%$ of the initial MAO amount was washed out by hot toluene for kaolin, thus at least twice as much as what is washed out in case of nanofillers. This difference could find origin in the much higher specific area the nanofillers developed, especially if some of the MAO molecules are able to diffuse in the interlayer, as already demonstrated by Tudor for non-modified clays [17].

The better activity of the catalytic complex attached to montmorillonite rather than to hectorite observed in Table 1 cannot be explained by the amount of MAO immobilized by the filler, which appears to be filler independent (Table 2). It may therefore be due to the nature (chemical structure, morphology, etc.) of the filler itself.

The reactivity of the TMA-depleted MAO towards hectorite has been estimated by measuring the volume of

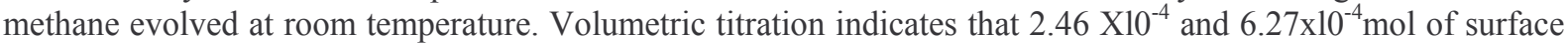
silanol groups per gram of filler react with alkylaluminum derivatives in heptane and toluene, respectively. It is clear that the reactivity of MAO towards hectorite depends on the solvent. When a good solvent for MAO (toluene) is used, reaction is 2.5 times more effective than in a non-solvent such as heptane. However, as far as the catalytic activity is concerned, the filler treatment with TMA-depleted MAO in heptane gives better activity (sample LD 10) than in toluene (LD 12) (Table 1). So, the solvent in which the filler is treated may deeply affect the way MAO reacts with the particulate support and ultimately the polymerization activity.

Table 2

Quantitative analysis of the attachment of MAO to the filler (polymerization conditions: see Table 1) Washed $\mathrm{MAO}\left(\mathrm{X} 10^{-3} \mathrm{moleA1}\right)-\mathrm{MAO}$ on fill $\begin{array}{lll}(\% \mathrm{~A} 1 \text { at start) } & \text { (\%A1 at start) } & \text { mole } / \mathrm{g})(\% \mathrm{~A} 1 \text { at start })\end{array}$

\begin{tabular}{lllll}
\hline LD 5 (hect.) & $5.80(29.5)$ & $0.57(2.9)$ & $5.36(67.6)$ & 129.5 \\
LD 7 (mont.) & $5.34(27)$ & $1.52(7.7)$ & $5.17(65.3)$ & 178.2 \\
\hline
\end{tabular}

\subsection{Characterization}

\subsubsection{Influence of hydrogen on the molecular weight}

Melt viscosity of the prepared composites has been evaluated through melt flow index. For samples LD 2- 8, none of the composites tested were able to melt and flow under the test conditions $\left(190{ }^{\circ} \mathrm{C}\right.$, under $\left.21.6 \mathrm{~kg}\right)$. This behavior is typical of ultra high molecular weight polyethylene, usually obtained under the synthesis conditions used. The melt flow index of the LD 9 and 10 composites, prepared in the presence of a small amount of hydrogen, can be measured, the following values have been measured: (i) LD 9: $\mathrm{MI}_{2}=0.007 \mathrm{~g} / 10 \mathrm{~min}$; $\mathrm{MI}_{10}=$ $0.11 \mathrm{~g} / 10 \mathrm{~min} ; \mathrm{MI}_{21}=0.67 \mathrm{~g} / 10 \mathrm{~min}$; and (ii) $\mathrm{LD} 10: \mathrm{MI}_{2}=0 ; \mathrm{MI}_{10}=0.06 \mathrm{~g} / 10 \mathrm{~min} ; \mathrm{MI}_{21}=0.35 \mathrm{~g} / 10 \mathrm{~min}$. They confirm that molecular hydrogen is an efficient transfer agent in the ethylene polymerization, which decreases the chain length of the PE produced and thus the melt viscosity of the matrix. Isolation of the PE matrix for SEC measurement has shown to be quite difficult. When attempting to dissolve the samples in 1,2,5-trichlorobenzene at $130{ }^{\circ} \mathrm{C}$ or higher temperature, a gel was usually obtained rather than a solution, prohibiting any isolation of $\mathrm{PE}$ for SEC analysis. Only a fraction of LD 9 (which showed the highest MFI values) has been successfully isolated and analyzed by SEC. $M_{n}$ of 77.000 and $M_{w} / M_{n}$ of 6.55 were accordingly found. The very broad molecular weight distribution might be explained, at

least partly, by the continuous decrease in the transfer agent $\left(\mathrm{H}_{2}\right)$ concentration which is consumed all along the polymerization. Similar observation was reported when the PFT was conducted with microfillers under comparable conditions [22].

\subsubsection{X-ray diffraction analysis}

Fig. 2 compares the XRD patterns for the native hectorite and the as-recovered HDPE/hectorite LD 5 and 9 composites. Although hectorite shows a broad peak centered at $6.84^{\circ}$, characteristic of a filler interlayer spacing of $12.8 \mathrm{~A}$, no diffraction peak is observed for the LD 5 composite in the $1.5-10^{\circ}$ angle region, indicating the loss of a layered structure and thus possibly the exfoliation of the silicate layers. Such an exfoliated structure of a non-modified clay in PE, that is theoretically described as thermodynamically unstable results from the fact the PE matrix is produced within the interlayer spacing, where the MAO and the catalyst is supposed to be located. In this case, while the PE chains grow, they tend to push the silicate layers apart from each other, resulting to the ultimate destruction of the layered organization. Analogous observation can be made for LD 9, based on a PE matrix with lower molecular weight. No diffraction peak corresponding to the original clay neither any peak attesting for an intercalated structure can be observed. However, the moderate slope of the curve in the small angle area (below $4^{\circ}$ ) may account for a large and irregular distribution of interlayer spaces. 


\subsubsection{Transmission electron microscopy observations}

Slides with a thickness around 70-80 nm have been prepared by ultra microtomy at $-130{ }^{\circ} \mathrm{C}$ and observed by TEM. These samples are extremely sensitive to the electron beam and most of them have been destroyed very rapidly, preventing micrographs from being taken.

Fig. 3 shows the TEM micrograph for the compression-molded LD 10 sample, that was cut perpendicularly to the pressing plane. Few nanometric particles can be observed, which gives evidence for at least partial exfoliation. Some larger scale observations indicate that exfoliated layers have tendency to be confined to finite domains surrounded by non-modified polyethylene. This type of morphology thus consists of discrete zones of exfoliated particles scattered in the PE matrix.

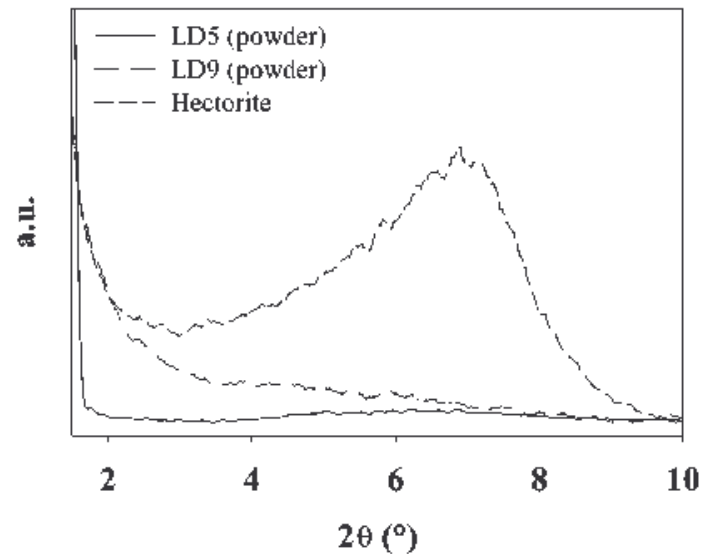

Fig. 2. XRD patterns for native hectorite and the as-recovered LD 5 and 9 nanocomposites. $M J M_{n}$

$\AA$,

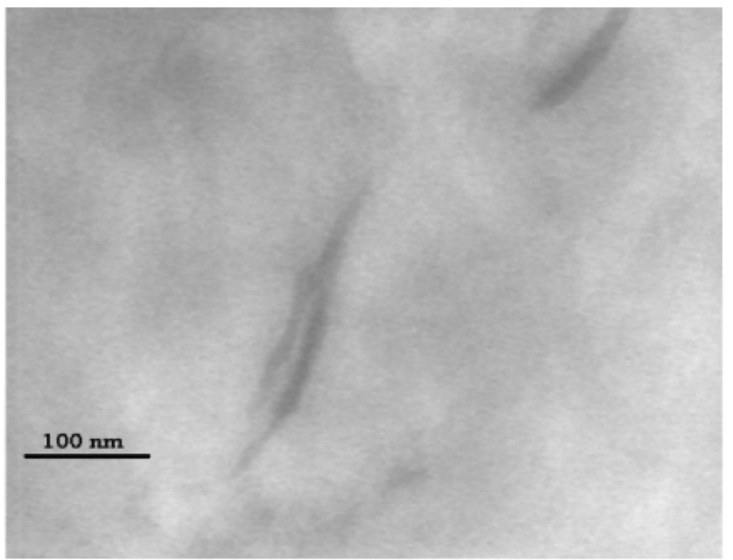

Fig. 3. TEM micrograph of the compression-molded LD 10 sample (slide perpendicular to the pressing plane).

\subsubsection{Mechanical properties}

The tensile testing of dumbbell-shaped samples has been carried out at an elongation rate of $20 \mathrm{~mm} / \mathrm{min}$. The main results are listed in Table 3 .

Clearly, the samples can be classified in two types of mechanical behavior, depending on the addition or not of hydrogen as a molecular mass regulator during the synthesis. The first group of samples, LD 2-8, prepared in absence of hydrogen and consisting of UHMWPE matrices as inferred by the MFI measurement, present several similar mechanical characteristics. No tensile yield is observed even though the tensile speed is decreased from 20 to $5 \mathrm{~mm} / \mathrm{min}$. No necking occurs, whereas some stress-hardening is noted at the larger strains. High stress at break together with medium elongation at break and relatively low Young's modulus are also observed. In contrast to what is often observed for nanocomposites [4], the Young's modulus of the UHMWPE-based composites prepared in this work is not higher than the modulus of the polymer itself (LD 1). Kaolin (LD 2), which is a 'microfiller', leads also to the same set of properties. This high homogeneity in the tensile behavior, whatever the nature and the amount of filler used implies that for this set of composites, the mechanical properties are essentially driven by the nature of the matrix. The typical behavior of UHMWPE matrix 
overcomes and levels off any influence of the nature and state of dispersion of the filler. The differences in strain and stress at break shown by LD 3 and 4 compared to samples of the LD 5-8 series are mainly due to a shorter molding time ( $7 \mathrm{~min}$ instead of $14 \mathrm{~min}$ ). In contrast, when the molecular weight is decreased by the addition of hydrogen (LD 9-13), yielding occurs and the mechanical properties (strain at break and Young's modulus) are improved. In these samples, necking occurs after yielding and cold drawing. LD 13 shows very high modulus and poor tensile properties in relation to a relatively high filler content (11.4\%). LD 12, of still a higher filler content $(13.0 \mathrm{wt} \%)$ is no longer processable, keeping its powdery form even after compression-molding at 240 ${ }^{\circ} \mathrm{C}$. In these samples, the molecular masses are reduced (the MFI can be measured for LD 9 and 10) and a clear effect of the filler concentration is evidenced. The higher value observed for the Young's modulus may reflect the presence of nanocomposite.

Moreover, the method used for the sample preparation has a direct influence on the mechanical properties, particularly on the Young's modulus, known to be highly dependent upon the existence of a nanocomposite structure. For instance, LD 9 has been shaped for testing according to two different methods, i.e. compressionmolding of the as-recovered powder (LD 9, Table 3) and compression-molding of the premelted composite collected after 5-min kneading at $190{ }^{\circ} \mathrm{C}$ with a 2-roll mill (LD 9b, Table 3). The roll-milled sample shows a Young's modulus $(0.89 \mathrm{GPa})$ lower than the compression-molded sample (modulus at $1.28 \mathrm{GPa}$ ). In order to account for this difference, the two processed samples as well as the original powdery nano-composite have been analyzed by XRD (Fig. 4). The obtained results are compared to XRD measurements carried out on a UHMWPE-based nanocomposite (LD 5) before and after melt processing (Fig. 6).

Table 3

Tensile properties of HDPE-based nanocomposites prepared by polymerization-filling technique $($ see Table 1$) \mathrm{h}=\mathrm{hectorite}, \mathrm{m}=$ montmorillonite, $\mathrm{k}=$ kaolin

Sample Filler (loading) (wt \%) Strain at yield (\%) Stress at yield (MPa) Strain at break (\%) Stress at break (MPa) Young's modulus (G

\begin{tabular}{|c|c|c|c|c|c|c|}
\hline LD1 & 0 & $\sim 6.0$ & $23.0 \pm 1.0$ & $244 \pm 13$ & $25.2 \pm 1.1$ & $0.69 \pm 0.05$ \\
\hline LD2 & $\mathrm{k}(2.3)$ & None & None & $225 \pm 17$ & $36.6 \pm 2.1$ & $0.60 \pm 0.01$ \\
\hline LD3 & $\mathrm{h}(4.2)$ & None & None & $132 \pm 5$ & $28.1 \pm 1.3$ & $0.35 \pm 0.01$ \\
\hline LD4 & $\mathrm{m}(3.3)$ & None & None & $147 \pm 8$ & $30.4 \pm 1.3$ & $0.72 \pm 0.08$ \\
\hline LD5 & $\mathrm{h}(3.8)$ & None & None & $205 \pm 32$ & $34.8 \pm 2.5$ & $0.64 \pm 0.10$ \\
\hline LD6 & $\mathrm{h}(4.0)$ & None & None & $230 \pm 10$ & $39.7 \pm 0.7$ & $0.63 \pm 0.05$ \\
\hline LD7 & $\mathrm{m}(3.9)$ & None & None & $145 \pm 37$ & $29.8 \pm 0.2$ & $0.66 \pm 0.10$ \\
\hline LD8 & $\mathrm{m}(4.1)$ & None & None & $178 \pm 13$ & $32.0 \pm 0.5$ & $0.59 \pm 0.03$ \\
\hline $\mathrm{LD}^{\mathrm{a}}$ & $h(3.4)$ & $\sim 6.5$ & $27.4 \pm 0.4$ & $467 \pm 47$ & $27.9 \pm 2.4$ & $1.28 \pm 0.01$ \\
\hline LD $9 b^{a, b}$ & h (3.4) & $\sim 6.5$ & $26.4 \pm 0.4$ & $458 \pm 33$ & $29.7 \pm 1.0$ & $0.89 \pm 0.13$ \\
\hline $\mathrm{LD} 10^{\mathrm{a}}$ & $\mathrm{h}(4.5)$ & $\sim 7.8$ & $26.8 \pm 0.3$ & $228 \pm 13$ & $25.7 \pm 0.9$ & $1.11 \pm 0.02$ \\
\hline LD $10 b^{\mathrm{a}, \mathrm{c}}$ & h (4.5) & $\sim 7.4$ & $27.1 \pm 0.5$ & $373 \pm 2$ & $33.2 \pm 0.5$ & $1.28 \pm 0.18$ \\
\hline $\mathrm{LD} 12^{\mathrm{a}}$ & $\mathrm{h}(13.0)$ & Cann & & & & \\
\hline $\mathrm{LD}_{13}{ }^{\mathrm{a}}$ & $h(11.4)$ & None & none & $3.1 \pm 0.9$ & $34.2 \pm 2.2$ & $2.48 \pm 0.24$ \\
\hline
\end{tabular}

${ }^{\mathrm{a}}$ Synthesized in the presence of hydrogen. ${ }^{\mathrm{b}}$ Premelting at $190^{\circ} \mathrm{C}$ with a two-roll mill. ${ }^{\mathrm{c}}$ Added with Irganox 1010.

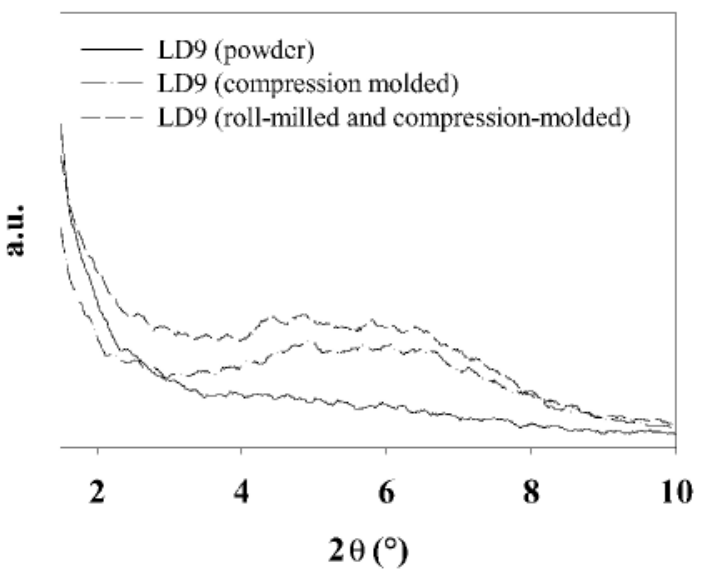

Fig. 4. XRD patterns for the LD 9 nanocomposite — the as-recovered powder; - -- after compression-molding of the powder and - - - after pre-melting of the powder on a roll-mill followed by compression-molding.

Whereas the LD 9 powdery sample shows no diffraction peak (which is representative of an exfoliated nanocompo-site), the two compression-molded samples (with and without premelting) display a very broad diffraction peak between 4 and $8^{\circ}$, evidencing the formation of repetitive structures with a broad distribution of interlayer spacings. The origin of these broad peaks may be found in the partial collapse of the exfoliated 
structure upon matrix melting. The broad peak, more intense in case of the melt-kneaded composite (LD 9b), possibly results from a more important collapse of the exfoliated structure as more time and energy has been brought to the system to reach a more thermo-dynamically stable state. Indeed, theoretical studies have shown that dispersions of relatively polar nanoscopic platelets within a non-polar matrix like PE, are unstable for thermodynamic reasons [24,25] and cannot be preserved in the melt. Separation of the silicate layers by PE chains is therefore thermodynamically unfavorable and the layers tend to collapse as soon as the composite is melted and sufficiently fluid. Even if the collapse of the exfoliated structure is evidenced, the maximum of the resulting diffraction peak is observed for the composite at a lower angle (ca. $5.5^{\circ}$ corresponding to ca. $16 \AA$ ) than for the original filler (inter-layer distance of $12.8 \AA$ ). This means that, after melting, some PE chains are thus remaining in between the silicate layers. The resulting new hybrid structure can give rise to extremely elongated morphologies, such as those observed by TEM for LD 10, after sample melting into the melt flow index apparatus (Fig. 5a) or for a nanocomposite filled by $9.0 \mathrm{wt} \%$ hectorite, produced at low ethylene pressure (1.7 bar) and premelted by a two-roll mill (Fig. 5b). This new morphology is characterized by a decrease in stiffness, as depicted by the drop in Young's modulus.

(a)

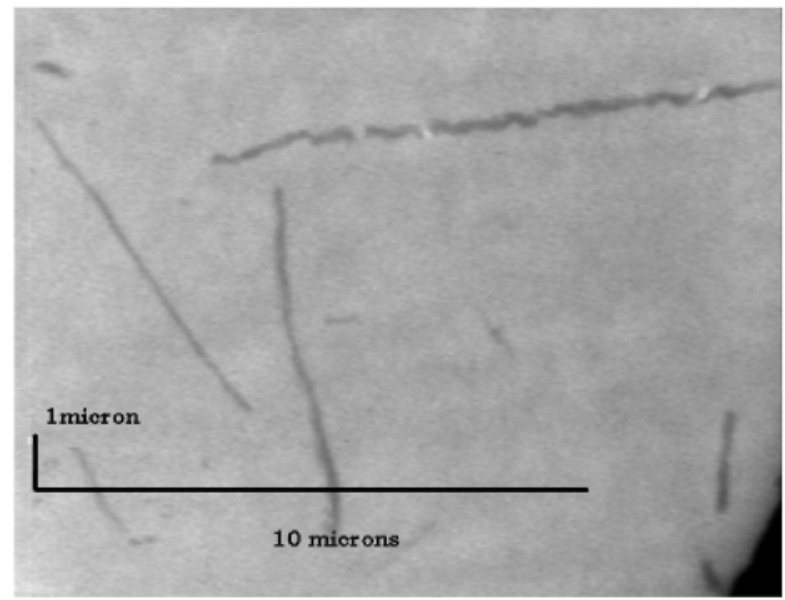

(b)

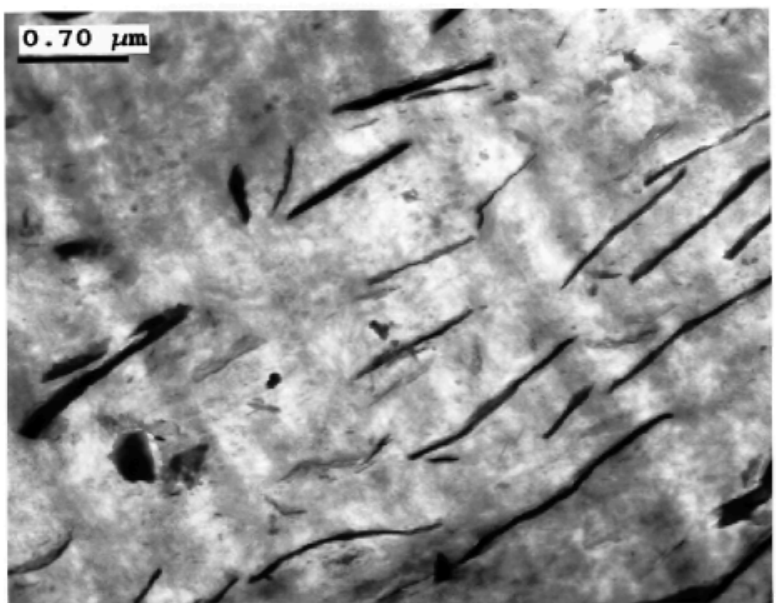

Fig. 5. TEM micrographs for: (a) LD 10 melted at $190{ }^{\circ} \mathrm{C}$ in the melt index apparatus (slide perpendicular to the polymer flow) (b) a HDPEbased nanocomposite produced under a low ethylene pressure (1.7 bar), after mechanical kneading $\left(5\right.$ min, $\left.190{ }^{\circ} \mathrm{C}\right)$ and compression-molding $\left(200{ }^{0} \mathrm{C}\right)$.

On a structural basis, one can note that the collapse of the exfoliated structure may be prevented by increasing the viscosity of the matrix. This is demonstrated in the case of LD 5 nanocomposite, based on UHMWPE. In this case, the molecular weight of the matrix is such high that it prevents collapse from occurring during compression-molding. As a result, no significant increase in the intensity of the XRD signal (Fig. 6) can be observed. The exfoliated state is therefore preserved for kinetic reasons.

Finally, the issue of the thermal stability of the composites has also been addressed. So, the LD 10 composite has been split in two fractions after filtration. The first fraction has been immediately dried, whereas the second one, LD 10b, has been redispersed in acetone added with ca. $0.02 \mathrm{wt} \%$ of Irganox 1010 (a commercial antioxidant). After acetone evaporation, LD 10b has been recovered and dried under vacuum. The improvement in all the 
mechanical properties (Table 3) clearly confirms the beneficial effect of the antioxidant.

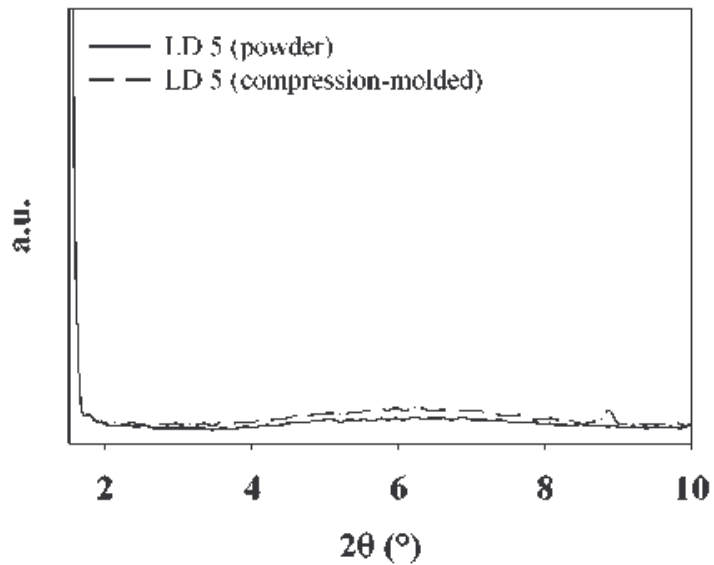

Fig. 6. XRD patterns for the LD 5 nanocomposite: — the as-recovered powder; - - after compression-molding of the powder

\subsubsection{Differential scanning calorimetry measurements}

The compression-molded LD 5-12 composites and the as-recovered powder LD 10 have been analyzed by DSC. Crystallinity has been quantitatively measured by subtracting the filler mass contribution, on the basis of a melting enthalpy for $100 \%$ crystalline PE of $293 \mathrm{~J} / \mathrm{g}$ [26]. Results are shown in Table 4.

As a rule, nanocomposites prepared in the presence of hydrogen display much higher degree of crystallinity and higher melting temperature. The prohibitively high viscosity of the samples prepared in absence of hydrogen (LD 2, 5-8) may account for a lower crystallinity. Moreover, an increase in the nanofiller content ( $13 \mathrm{wt} \%$ for LD 12) clearly results in a dramatic increase in crystallinity, parallel to a higher melting temperature, which suggests a nucleating activity of the nanofiller.

XRD analysis for LD 10 in the $10-30^{\circ}$ range of $2 \theta$ shows only two peaks at 21.5 and $23.9^{\circ}$, that correspond to the (200) and (110) planes of the orthorhombic cell of PE. No trace of monoclinic or hexagonal cells may be found, which precludes extended chain crystallization to be responsible for higher melting temperatures.

In order to account for the high melting temperature of the LD 9, 10 (powdery and compression-molded) and 12 samples, the possible influence of the heating rate on the DSC traces has been studied for the LD 10 and 12 composites (Table 5). DSC traces recorded at $20^{\circ} \mathrm{C} / \mathrm{min}$ are shown in Fig. 7. A decrease in the melting temperature by $13{ }^{\circ} \mathrm{C}$ is observed when the heating rate is decreased from 20 to $5{ }^{\circ} \mathrm{C} / \mathrm{min}$. Only a decrease of 2 ${ }^{\circ} \mathrm{C}$ is observed in case of a commercially available HDPE under the same conditions. These data show that the higher melting temperature in the compressed-molded LD 10 and 12 samples results from a slow heat transfer through the composite, the difference in the crystallinity between the two samples still being due to the suspected nanofiller nucleating ability. This observation suggests that the nanofiller and the way it is dispersed within the polymer can modify the heat transfer properties. A preferential orientation of the filler, parallel to the pressing plane could result in the building up of a heat barrier. For the LD 3-8 samples prepared in absence of hydrogen, the matrix is too much viscous for the filler to get a preferential orientation, and the melting temperature remains close to the value observed for the powdery sample.

Table 4

Melting temperature and degree of crystallinity of compression-molded composites

\begin{tabular}{llllll}
\hline Sample & Melting $T\left({ }^{\circ} \mathrm{C}\right)$ & Crystallinity $(\%)$ & Sample & Melting $T\left({ }^{\circ} \mathrm{C}\right)$ & Crystallinity $(\%)$ \\
\hline LD2 & 142.5 & 36.7 & LD9 $^{\mathrm{a}}$ & 149.3 & 51.7 \\
LD5 & 143.4 & 38.7 & LD 10 & 152.2 & 43.3 \\
LD6 & 143.5 & 40.6 & LD 10 & 144.7 & 59.2 \\
LD7 & 145.1 & 39.0 & LD 12 & 154.4 & 77.5 \\
LD8 & 142.2 & 41.4 & & & \\
\hline
\end{tabular}

${ }^{\mathrm{a}}$ Composites prepared in the presence of hydrogen (see Table 1). ${ }^{\mathrm{b}}$ Powdery sample. 
Table 5

Influence of the heating rate on the DSC thermograms of the compression-molded LD 10 and 12 samples

\begin{tabular}{llll}
\hline Sample & Heating rate $\left({ }^{\circ} \mathrm{C} / \mathrm{min}\right)$ & Melting temperature $\left({ }^{\circ} \mathrm{C}\right)$ & Crystallinity $(\%)$ \\
\hline LD 10 & 20 & 152.2 & 43.3 \\
& 5 & 139.1 & 42.4 \\
LD 10 (powder) & 20 & 144.4 & 59.2 \\
LD 12 & 20 & 154.4 & 77.4 \\
& 5 & 139.3 & 67.7
\end{tabular}

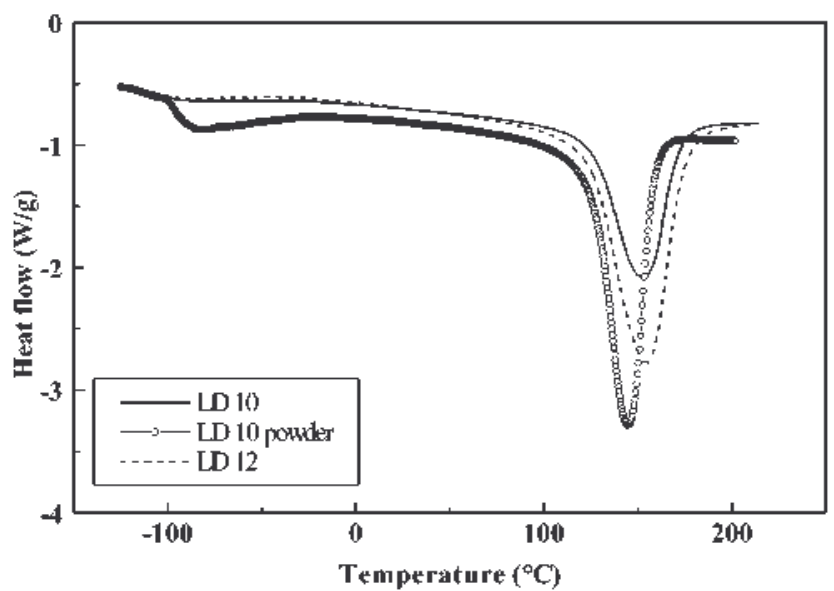

Fig. 7. DSC traces for the LD 10 and LD 12 compression-molded samples and for the LD 10 powdery sample, at a heating rate of $20^{\circ} \mathrm{C} / \mathrm{min}$.

\subsubsection{Dynamic mechanical analysis}

DMA at fixed frequency $(1 \mathrm{~Hz})$ has been conducted in the temperature range of $-120^{\circ} \mathrm{C}$ to $150{ }^{\circ} \mathrm{C}$. Plots of the storage and $\tan \delta$ against temperature have been recorded for several samples and shown in Figs. 8 and 9, respectively.

Low storage modulus values are recorded for the LD 5 that consist of a UHMWPE matrix (Fig. 8). In case of polyethylene of lower molecular weight, the effect of the nanofiller is readily observed. For instance, the HDPE/ hectorite nanocomposite LD 9 displays higher storage moduli compared to LD 5 in the whole temperature range although its filler content is lower. This observation qualitatively agrees with the tensile properties measured at room temperature. When the hectorite content is increased (LD 10 and 13), the storage modulus dramatically increases, especially below ca. $80{ }^{\circ} \mathrm{C}$. Typical values of moduli at $-50{ }^{\circ} \mathrm{C}$, thus in the 'plateau' region between the $\gamma$ and $\beta$ transitions (see below), are 0.83, 0.95, 1.26 and 2.05 GPa for LD 5, LD 9, LD 10 and LD 13, respectively. The large increase in moduli is a common characteristic feature of layered clay-based nanocomposites in which a small amount of platelets with a high aspect ratio is enough to improve the mechanical properties [4] remarkably.

Fig. 9 illustrates how $\tan 8$ depends on the filler content for four nanocomposites. Three transitions are observed at ca. $-115,-25$ and $70{ }^{\circ} \mathrm{C}$. They can be assigned to the $\gamma, \beta$ and $\alpha$ relaxations of polyethylene, respectively. The $\gamma$ relaxation is commonly ascribed to the glass transition [27] and therefore concerns the amorphous fraction of the polymer matrix. The $\beta$ relaxation is related to the glass-rubber transition of constrained non-crystalline chain segments [28] and the $\alpha$ process has to do with phenomena such as intracrystalline relaxation and sliding of tied chains within crystalline blocks [29].

As shown in Fig. 9, all these relaxations change with the filler content, which suggests that the nanofiller influences not only the properties of the amorphous polyethylene but also the crystalline regions. The small $\alpha$ transition observed for the LD $\mathbf{5}$ sample can be directly related to the lower crystallinity as measured by DSC. 


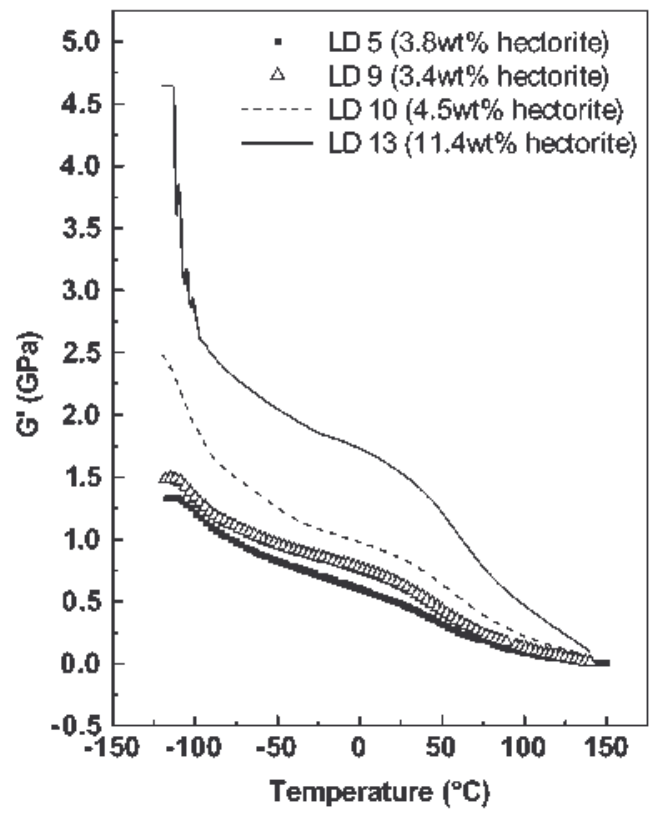

Fig. 8. Temperature dependence of the shear storage modulus for the compression-molded LD 5, 9, 10 and 13 samples.

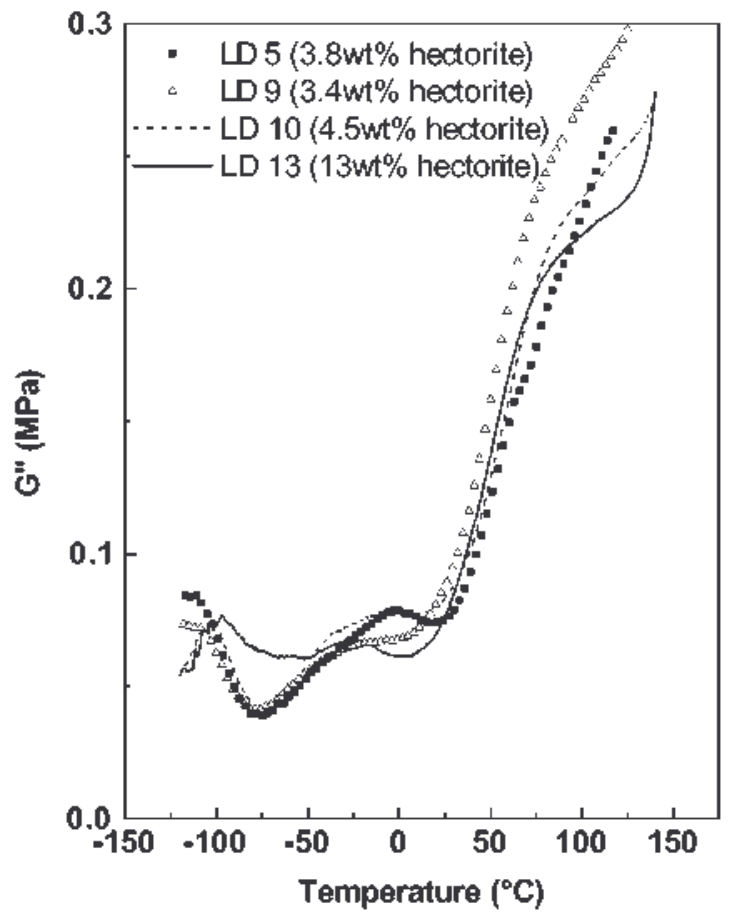

Fig. 9. Temperature dependence of $\tan \boldsymbol{\delta}$ for the compression-molded LD 5, 9, 10 and 13 samples.

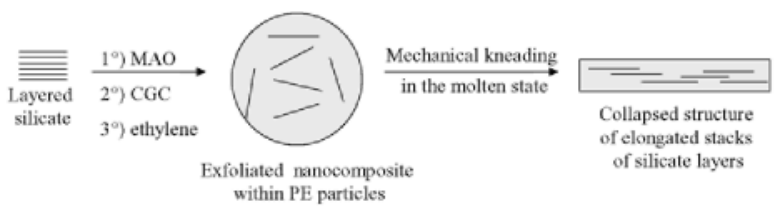

Fig. 10. Sketch for the dispersion and collapse of the silicate layers in PE produced by the PFT.

\section{Conclusions}

This study has shown that nanocomposites consisting of polyethylene and non-modified layered silicates (hectorite, montmorillonite) can be prepared by the PFT catalyzed by metallocene/MAO complex. Large amount of MAO has to be attached to the filler in order to impart enough activity to the polymerization catalyst and to produce composites with a low filler content. The MAO has to be reacted with the filler in a non-solvent for MAO (e.g. heptane), because in a solvent, such as toluene, the filler surface is passivated and most of the 
aluminoxane is lost during washings as result of molecular rearrangement.

In the absence of hydrogen, which acts as transfer agent in the ethylene polymerization, ultra high molecular weight $\mathbf{P E}$ is formed and dictates the mechanical properties of the composites. Addition of hydrogen expectedly decreases the molecular weight of $\mathbf{P E}$ and leads to composites with improved tensile and shear properties, i.e. a marked increase in the Young's and shear moduli and an improved strain behavior. At constant nanofiller loading, the origin for these improvements has to be found in the fine dispersion and preferential orientation of the nanoparticles. This type of exfoliated nanocomposites is however, thermodynami-cally unstable. Indeed, for sufficiently fluid PE matrices, the exfoliated structure collapses in the melt into a non-regular intercalated structure as ideally sketched in Fig. 10.

\section{Acknowledgements}

M.A. and RJ. are grateful to the 'Services Federaux des Affaires Scientifiques, Techniques et Culturelles' for general support to CERM in the frame of the 'Poles d'Attraction Interuniversitaires: Polymeres'. RJ. thanks The Dow Chemical Company for support and a fellowship to M.A. This work was performed in part under the support of the US Department of Commerce, National Institute of Standards and Technology, Advanced Technology Program, Cooperative Agreement Number 70NANB7H3028.

\section{References}

[1] Giannelis EP. Adv Mater 1996;8:29-35.

[2] Gilman JW. Appl Clay Sci 1999;15:31-49.

[3] LeBaron PC, Wang Z, Pinnavaia TJ. Appl Clay Sci 1999;15:11-29.

[4] Alexandre M, Dubois P. Mater Sci Engng Reports 2000;28:1-63.

[5] Jimenez G, Ogata N, Kawai H, Ogihara T. J Appl Polym Sci 1997;64:2211-20.

[6] Ogata N, Kawakage S, Ogihara T. J Appl Polym Sci 1997;66:573-81.

[7] Ogata N, Jimenez G, Kawai H, Ogihara T. J Polym Sci: Part B: Polym Phys 1997;35:389-96.

[8] Liu LM, Qi ZN, Zhu XG. J Appl Polym Sci 1999;71:1133-8.

[9] Burnside SD, Giannelis EP. Chem Mater 1995;7:1597-600

[10] Vaia RA, Ishii H, Giannelis EP. Chem Mater 1993;5:1694-6.

[11] Vaia RA, Jandt KD, Kramer EJ, Giannelis EP. Chem Mater 1996;8:2628-35.

[12] Hasegawa N, Kawasumi M, Kato M, Usuki A, Okada A. J Appl Polym Sci 1998;67:87-92.

[13] Kawasumi M, Hasegawa N, Kato M, Usuki A, Okada A. Macro-molecules 1997;30:6333-8.

[14] Kojima Y, Usuki A, Kawasumi M, Okada A, Kurauchi T, Kamigaito O. J Polym Sci Part A: Polym Chem 1993;31:983-6.

[15] Messersmith PB, Giannelis EP. J Polym Sci: Polym Chem 1995;33:1047-57.

[16] Akelah A, Moet A. J Mater Sci 1996;31:3589-96.

[17] Tudor J, Willington L, O'Hare D, Royan B. Chem Commun 1996:2031-2.

[18] von Werne T, Patten TE. J Am Chem Soc 1999;121:7409-10.

[19] Bergman JS, Chen H, Giannelis EP, Thomas MG, Coates GW. Chem Commun 1999:2179-80.

[20] Heinemann J, Reichert P, Thomann R, Mulhaupt R. Macromol Rapid Commun 1999;20:423-30.

[21] Alexandre M, Dubois P, Garcia Marti M, Jerome R. Submitted for publication.

[22] Alexandre M, Martin E, Dubois P, Garcia-Marti M, Jerome R. Macromol Rapid Commun 2000;21:931-6.

[23] Letourneur J-F. PhD Thesis. University Claude Bernard, Lyon, 1995.

[24] Vaia RA, Giannelis EP. Macromolecules 1997;30:7990-9.

[25] Balazs AC, Singh C, Zhulina E, Lyatskaya Y. Ace Chem Res 1999;8:651-7.

[26] Flory PJ, Vrij J. J Am Chem Soc 1963;85:3548.

[27] Takayanagi M. Proceedings of the Fourth International Congress of Rheology. Interscience, New-York, 1964.

[28] Boyer RF. J Macromol Sci: Phys Part B 1973;B8:503. [29] Oven AJ, Ward IM. J Macromol Sci: Phys Part B 1973;B7:417. 